\title{
Education of Chinese Traditional Operas in Colleges from the Perspective of Cultural Identity-A Case Study of Lv Opera
}

\author{
$\mathrm{Xu}$ Wang ${ }^{1, *} ;$ Xinhui Song ${ }^{2}$ \\ ${ }^{1}$ School of Literature,Law and Business, Shengli College China University of Petroleum, Dongying, Shandong 257061, \\ China \\ ${ }^{2}$ School of Literature,Law and Business, Shengli College China University of Petroleum, Dongying, Shandong 257061, \\ China \\ *Corresponding author. Email: 1453454677@qq.com
}

\begin{abstract}
\section{Current traditional opera education in colleges and cultural identity for $L v$ opera among college students}

Traditional operas account for an important part of Chinese intangible cultural heritages and are embodiments of a nation's soft power. Lv opera, a national intangible cultural heritage, drives from Dongying in Shandong province, China. The opera is simple, unadulterated, fluent and easy to learn, and is thus popular among the local people. As time moves forward, Lv opera has unwittingly become an indispensable part of the local culture of Shandong. Yet, as most of the audience are old people in rural areas, and college students largely know little about this form of art. They pay little attention it Lv opera and show no cultural identity for it, which results from lack of opera training in colleges. Now, the market for Lv opera is shrinking and old Lv opera masters can find no one to inherit this art. College students are the major force of social development, so they are both capable and liable to learn Lv opera and promote its development. Therefore, it is important for colleges to promote education of traditional operas and cultivate the students' cultural identity of this form of art. By encouraging colleges to promote education of traditional operas, this paper aims to cultivate the college students' cultural identity and thus achieve the goal of "education of Lv opera".

Keywords: cultural identity, education of opera, Lv drama culture

\subsection{Development status of opera education in colleges}

In these years, China has made efforts to protect and inherit operas, and have made some achievements in this regard, but there are still many problems in opera education in colleges [1]. For instance, the current education system has played a limited role in inheritance of operas. Most colleges focus on research achievements and provide few courses on operas for students, and some even pay no attention to education of operas. These problems have to be solved. How to find a proper way for education of operas in light of the college students' physical and psychological features is an issue that needs to be addressed by colleges.

\subsection{Current situation of college students' recognition for and attitude to Lv opera}

\begin{abstract}
Research shows that current college students show little understanding of or interest in Lv opera. First of all, they pay little attention to traditional operas and show no interest in learning operas [2] ; secondly, they have little access to Lv operas, so it is hard for them to appreciate this art; last, they do not recognize the value of $\mathrm{Lv}$ opera some even consider traditional operas old-fashioned and not suitable for the contemporary world. [3]
\end{abstract}

\section{Significance of cultural identity for opera education in colleges}

In a sense, to analyze the opera education in colleges from the angle of cultural identity follows the guidance of the 13th Five-year Plan and has practical significance to increase the college students' cultural identity for Lv opera. [4] In the Cultural Reform Planning of the"13th Five-Year 
Plan" Period issued by the Culture Administration of Shandong province, the government encourages innovation of excellent traditional culture in Shandong and initiatives to protect, develop, popularize and inherit excellent traditional cultures so as to realize overall societal development [5] . For Lv opera, a national intangible cultural heritage, we should extend the audience among college students to promote inheritance and development of this art. College students are the major force of social production and are more creative to develop products that can reflect the culture of Shandong and the features of the times.

The major force to inherit traditional Chinese culture are college students aged between 18 and 25. They are welleducated and are suitable for cultural education. To develop cultural identity for Lv opera among college students will play a promoting role in cultural and art education in colleges. [6]

To cultivate cultural identity among college students can help promotion and development of Lv opera, improve the college students' recognition for Lv opera, increase their interest in this form of art, extend the audience of Lv opera and enhance the force of cultural inheritance and development.

Meanwhile, improvement of cultural identity can improve the publicity rate of Lv opera and extend the channel for spread of Lv opera [7] ; it can also increase the local cultural confidence and the people's sense of belonging, making the opera more popular among the locals. It will foster a sense of pride among college students for Lv opera, and thus draw more talents to inherit and develop this art form. In this way, we can provide a foundation for cultural development and inheritance of traditional opera culture in the new age of socialism.

\section{APPLICATION OF CULTURAL IDENTITY IN OPERA EDUCATION AMONG COLLEGE STUDENTS}

It is necessary to investigates the college students' cultural identity for Lv opera, make use of college resources to further opera education [8] and improve the college students' cultural identity for Lv opera.

\section{1. the special stage of college students}

Studies show that contemporary college students have high learning abilities and show maturity in self-awareness, but they are subjective and have large mood swings, in need of mood control [9]. They show high passion for new things and are eager to learn more.

Thus, we can take corresponding measures to conduct opera education.
By surveys, this study analyzes the college students' emotional identity [10] and preference for $\mathrm{Lv}$ opera to provide a basis for integration of cultural identity with cultural education. By developing new ways of opera education, we can introduce Lv opera to campus life, inspire their interest, offer solutions for extending opera audience and training performers, orient the operas to college students' preferences. In this way, we can increase the college students' cultural identity for Lv opera, turn college students from passive receivers of art to active subjects of art, making education of Lv opera practically meaningful. [11]

\subsection{Proposal of education of Lv opera}

Intangible cultural heritages are drawing increasing research attention. In "Development and Dilemma of Lv opera art", the author Pan Yu points out that Lv opera is an important carrier of culture of Shandong and is of great cultural and historic values. In "Development and Inheritance of Lv opera performance art" [12] , the author Lan Xiaojun argues that this opera reflect the productivity, cultural value and aesthetic value of Shandong people, and it is a "spiritual home" we should protect.

Sources reveal that at the start of 2019, Sichuan Normal University was the first to propose the idea of "opera education" [13] and the university was then appointed as a pilot area for reform of cultural and art education. The Dean of Art School said that to include inheritance of intangible cultural heritages to cultural and art education is in consistence with "the root of education, and to introduce inheritance of intangible cultural heritages into Chinesestyle cultural education in colleges can promote sustainable development of excellent traditional culture and boost the initiatives to build China into a culturestrong and talent-strong country" [14] . By analyzing Lv opera, a national intangible cultural heritage, this paper hopes to promote cultural and art education in colleges, inspire the college students' cultural identity, advance education of Lv opera and realize sustainable development of Lv opera culture. 
focus of this paper is "Lv opera education" [20] . As the Chinese-style socialist society enters a new age, colleges, as the main venue to train talents, should keep up with the pace of the times and advance social development. For "Lv opera education" in this new age, colleges should promote development of traditional Chinese operas, take into account of college students' life and innovate the classes and teaching methods.

Fund projects : key topics of art science in Shandong province in 2019 : A Study on the Coincidence and Popularization of $\mathrm{Lv}$

Opera Culture in Shandong Youth Group from the Perspective of New Media ( Project number : ZH201906004)

\section{REFERENCES}

[1]Investigation and Analysis on the Current Situation of Aesthetic Education in Local Colleges and Universities .[J]. Li Linhong. Education and Teaching Forum . 2020(03)

[2]Study on Aesthetic Education Teaching in Colleges and Universities from the Perspective of Local Culture Inheritance .[J]. Xiao Qing, Geng Guanghan, Wu Yan, Wang Yinyin.Anhui Architecture . 2020(01)

[3]A Preliminary Study on Strengthening the Aesthetic Education Courses in Colleges and Universities under the Background of Innovative Education -- Taking Hehai University as an Example .[J]. Wang Xiaoxuan,Chen Weigang,Chen Zhi.Curriculum Education Research. 2020(03)

[4On the construction of the pattern of the spread of intangible cultural heritages in modern opera-- Take the art communication of Shandong $\mathrm{Lv}$ opera as an example [J]. Zhang Wenwen. Human World . 2019(22)

[5]The aesthetic style of Lv Opera Art .[J]. Wang Wei . Qilu Arts Court . 2019(05)

[6The cognitive deviation and correction of college students'traditional culture [J]. Kong Wei, Zhang Sanping.School party building and Ideological Education . 2018(23)

[7]Research on the development dilemma and Countermeasures of Shandong Lv Opera Art.[J]. Yuan Nan.Drama home. 2018(22)

[8]A Study on the Mechanism of Psychological Identity of Chinese Excellent Traditional Culture among Contemporary College Students .[J]Liu Xiaojie.Journal 
Universities in the Internet Age .[J]Zhang Bohan. Communication world . 2019(11)

[20]The Value of Intangible Cultural Heritage in College Aesthetic Education and Its Realization Path .[J]Zhou Qiang. Journal of Nanjing University of Technology (Social Sciences Edition) . 2019(04)

[10]A Study on the Mechanism of Psychological Identity of Chinese Excellent Traditional Culture among Contemporary College Students .[J]Liu Xiaojie.Journal of Huaihai Institute of Technology (Humanities and Social Sciences Edition) . 2016(02)

[11]A Strategic Study of College Students'Aesthetic Education Course -- Taking Art Education of Suzhou University as an Example .[J]Huo Yunzhe.Contemporary music . 2019(12)

[12]The Dilemma and Implementing Strategies of College Students'Educational Education from the Perspective of "Traditional Culture Campus Fever "-Taking Tonghua Normal College as an Example .[J]PanYuanyuan.Comparative study of cultural innovation . 2019(30)

[13]An Analysis of the Practical Path of Music to Enhance Students'Humanistic Quality in Aesthetic Education .[J]Lin Xiaofang.Northern music . 2017(03)

[14]An Analysis of the Way of Aesthetic Education of College Students'Thoughts .[J]Yang Kun,Zhou Shuai,Liu Yangkaiyue,Li Zhenyang. Ability and Wisdom . 2018(15)

[15]Thoughts on Carrying out the Concept of Cultural Inheritance in Aesthetic Education in Colleges and Universities .[J]Xu Jing.Journal of China Youth Political College . 2013(03)

[16]The Present Situation and Development Countermeasures of the Major of Music Teachers'Education in Colleges and Universities . $[\mathrm{J}] \mathrm{Li}$ Ying. Art assessment . 2013(03)

[17]Aesthetic Education and the Growth of College Students .[J]Xue Hong. Journal of Chongqing University (Social Sciences Edition) . 2017(05)

[18]On the Importance and Urgentness of Aesthetic Education in Colleges and Universities in the New Period .[J]Jianli Ma, Jianming Feng. Journal of Shanxi Radio and Television University . 2019(02)

[19]The Practical Problems and Countermeasures of Aesthetic Education Teaching in Colleges and 